\title{
Hypothermia following antipsychotic drug use
}

\author{
Rob J. van Marum • Michelle A. Wegewijs • \\ Anton J. M. Loonen • Erna Beers
}

Received: 1 September 2006 / Accepted: 7 March 2007 / Published online: 31 March 2007

(C) Springer-Verlag 2007

\begin{abstract}
Objective Hypothermia is an adverse drug reaction (ADR) of antipsychotic drug (APD) use. Risk factors for hypothermia in ADP users are unknown. We studied which risk factors for hypothermia can be identified based on case reports.

Method Case reports of hypothermia in APD-users found in PUBMED or EMBASE were searched for risk factors. The WHO international database for Adverse Drug Reactions was searched for reports of hypothermia and APD use.

Results The literature search resulted in 32 articles containing 43 case reports. In the WHO database, 480 reports were registered of patients developing hypothermia during the use of APDs which almost equals the number of reports for hyperthermia associated with APD use $(n=524)$. Hypothermia risk seems to be increased in the first days following start or dose increase of APs. APs with strong 5-HT2 antagonism seem to be more involved in hypothermia; $55 \%$ of hypothermia reports are for atypical antipsychotics. Schizophrenia was the most prevalent diagnosis in the case reports.

Conclusion Especially in admitted patients who are not able to control their own environment or physical status, frequent measurements of body temperature (with a thermometer that can measure low body temperatures) must be performed in order to detect developing hypothermia.
\end{abstract}

R. J. van Marum $(\bowtie) \cdot$ M. A. Wegewijs

Geriatric Department, University Medical Centre,

P.O. Box 85500, 3508 AB Utrecht, The Netherlands

e-mail: r.j.vanmarum@umcutrecht.nl

\author{
A. J. M. Loonen \\ Department of Pharmacotherapy in Psychiatric Patients, \\ University of Groningen, Groningen, \\ The Netherlands \\ E. Beers \\ Netherlands Pharmacovigilance Centre Lareb, \\ 's-Hertogenbosch, The Netherlands
}

Keywords Antipsychotic agents · Hypothermia .

Thermoregulation $\cdot$ Adverse drug effect $\cdot$ Schizophrenia

\section{Introduction}

Antipsychotic drugs (APDs) can influence thermoregulation. Even before its psychotropic properties were clear in the early 1950s, the first manufactured APD, chloropromazine, was used to suppress compensatory responses to body cooling in surgery (artificial hibernation) [1].

The hypothermic effects of APDs seem less well known than the hyperthermic effects (e.g., malignant neuroleptic syndrome). Besides occasional case reports, little emphasis has been placed in scientific literature on hypothermia as adverse drug reaction (ADR). To our knowledge, a review of all reported and published cases of antipsychotic associated hypothermia has not yet been published.

\section{Methods}

The WHO international database for Adverse Drug Reactions was searched for reports of hypothermia and APD use (ATC-code N05A, with exclusion of lithium). The data in the database are collected from 77 countries participating in the WHO Program for International Drug Monitoring. This database comprises more than 3.5 million case reports, to which around 50,000 new reports are added quarterly. The relationship between the APD and hypothermia is evaluated by calculating the Reporting Odds Ratios (RORs) and 95\% confidence intervals $(95 \% \mathrm{CI})$ in a case/non-case design. The ROR compares the frequency of the reported ADR for a certain drug with the frequency of reports of that adverse drug reaction for all other drugs in the database. Reports 
concerning hypothermia were considered as cases, all other reports as non-cases. Index reports included all reports on an APD (ATC code beginning with N05A, with exclusion of lithium), all other reports were controls. When the number of reports of hypothermia in association with the APD is high and the number of reports of hypothermia in association with other drugs is low, ROR will be high. This also happens when the number of reports of other ADRs in association with the APD is low and the number of reports of other ADRs in association with other drugs is low. Since the vast majority of cases in the WHO database do not contain any details on indication of drug use, start and/or end dates and outcome, these factors cannot be analyzed with data from the WHO database. To get more information regarding characteristics of patients developing hypothermia during APD use, we performed a literature search in Medline and Embase for case reports with search terms "(antipsychotic OR neuroleptic) AND (hypothermia OR body temperature regulation), with no selection on date or language. From these articles, we searched the references
Table 1 Antipsychotic drugs and hypothermia: reports from the WHO database
${ }^{a} \operatorname{ROR}=(\mathrm{a} / \mathrm{c}) /(\mathrm{b} / \mathrm{d}) ;(\mathrm{a}=$ no. of reports of adverse drug reaction with suspected drug;

$b=$ no. of reports of adverse

drug reaction in total database;

$\mathrm{c}=$ no. of reports regarding the suspected drug in database; $\mathrm{d}=$ total no. of reports in database). ROR is only calculated for APDs with three or more reports

\begin{tabular}{|c|c|c|c|}
\hline Antipsychotic drug & $\begin{array}{l}\text { Number of reports } \\
\text { for hypothermia }\end{array}$ & $\begin{array}{l}\text { Number of reports for } \\
\text { any ADR with this drug }\end{array}$ & $\begin{array}{l}\text { Reported OR }(\mathrm{CI})^{\mathrm{a}} \\
\text { for ADRs with } \geq 3 \text { reports }\end{array}$ \\
\hline \multicolumn{4}{|l|}{ Tioxanthenes } \\
\hline Zuclopenthixol & 13 & 1094 & $15.88(9.18-27.47)$ \\
\hline Flupenthixol & 6 & 1677 & $4.73(2.12-10.55)$ \\
\hline Chlorprothixen & 4 & 502 & $10.58(3.95-28.31)$ \\
\hline Tiotixene & 3 & 904 & $4.38(1.41-13.62)$ \\
\hline Clopenthixol & 2 & 293 & - \\
\hline \multicolumn{4}{|l|}{ Phenothiazines } \\
\hline Thioridazine & 23 & 4436 & $6.90(4.57-10.41)$ \\
\hline Chlorpromazine & 16 & 6182 & $3.43(2.09-5.60)$ \\
\hline Levomepromazine & 11 & 2348 & $6.21(3.43-11.24)$ \\
\hline Cyamemazine & 9 & 1197 & $9.99(5.18-19.27)$ \\
\hline Periciazine & 8 & 430 & $25,00(12.41-50.36)$ \\
\hline Pipothiazine & 3 & 197 & $20.36(6.50-63.71)$ \\
\hline Fluphenazine & 3 & 2656 & $1.49(0.48-4.62)$ \\
\hline Trifluoperazine & 3 & 1895 & $2.09(0.67-6.48)$ \\
\hline Perphenazine & 2 & 1522 & - \\
\hline Prochlorperazine & 2 & 4451 & - \\
\hline Promazine & 2 & 307 & - \\
\hline Mesoridazine & 1 & 215 & - \\
\hline \multicolumn{4}{|l|}{ Butyrofenones } \\
\hline Haloperidol & 32 & 10543 & $6.21(3.43-11.24)$ \\
\hline Pipamperone & 10 & 546 & $24.62(13.16-46.07)$ \\
\hline Droperidol & 2 & 1178 & - \\
\hline Benperidol & 1 & 146 & - \\
\hline \multicolumn{4}{|l|}{ Benzamides } \\
\hline Tiapride & 5 & 596 & $11.14(4.62-26.89)$ \\
\hline Sulpiride & 4 & 1828 & $2.89(1.08-7.70)$ \\
\hline Amisulpiride & 1 & 1514 & - \\
\hline Sultopride & 1 & 72 & - \\
\hline \multicolumn{4}{|l|}{ Others } \\
\hline Loxapine & 4 & 928 & $5.70(2.13-15.23)$ \\
\hline Pimozide & 3 & 628 & $6.31(2.03-19.65)$ \\
\hline Zotepine & 2 & 260 & - \\
\hline Prothipendyl & 1 & 93 & - \\
\hline Penfluridol & 1 & 58 & - \\
\hline \multicolumn{4}{|l|}{ Atypical } \\
\hline Risperidone & 129 & 18431 & $9.65(8.09-11.52)$ \\
\hline Clozapine & 68 & 44255 & $2.05(1.61-2.61)$ \\
\hline Olanzapine & 44 & 16090 & $3.65(2.71-4.91)$ \\
\hline Quetiapine & 21 & 5374 & $5.19(3.38-7.98)$ \\
\hline Aripiprazole & 11 & 4566 & $3.18(1.76-5.76)$ \\
\hline Ziprasidone & 8 & 2963 & $3.57(1.78-7.15)$ \\
\hline
\end{tabular}


for missing articles. Two reviewers judged all case reports. All relevant case reports were studied for patient, drug and environmental characteristics.

\section{Results}

In the WHO database, in January 2007, 480 reports were registered of patients developing hypothermia during the use of APDs. Characteristics of these reports are presented in Table 1. In the same period, 524 reports of hyperthermia associated with antipsychotic drug use were registered. Based on the reports, no specific pharmacological subgroup can be associated with an increased risk for hypothermia. Atypical antipsychotics are responsible for $55 \%$ of the reports, but this is mainly attributable to risperidone. Risperidone alone was responsible for $27 \%$ of all reports. A remarkable high association is found for pipamperone (ROR:24.62; 95\% CI 13.16-46.07), an antipsychotic drug mainly used in Europe.

The literature search resulted in 32 articles containing 43 case reports (December 2006) [3-34] from which characteristics are summarized in Table 2. Hypothermia following antipsychotic drug use is not associated with a specific age group. Reported ages vary from 0 to 90 years. In most cases, hypothermia is detected shortly following the start or dose increase of an antipsychotic drug. Most patients suffered from schizophrenia.

Table 2 Characteristics of cases with hypothermia following antipsychotic drug use in literature (43 case reports, 46 episodes)

\begin{tabular}{ll}
\hline Characteristics & Data \\
\hline Male & $41 \%$ \\
Age: mean (SD) & $49(23.0)$ \\
& Range $0-90$ years \\
Reported body temperature: mean (SD) & $32,6^{\circ} \mathrm{C}(2.7)$ \\
& Range 20.0-36.1 ${ }^{\circ} \mathrm{C}$ \\
Diagnosis known $(n=35)$ & \\
Schizophrenia & $51 \%$ \\
Mental retardation & $11 \%$ \\
Bipolar disorder & $11 \%$ \\
Dementia & $11 \%$ \\
Drug change Start or dose increase & $80 \%$ \\
No change & $16 \%$ \\
Interval drug change detection hypothermia & \\
$<2$ days & $57 \%$ \\
$2-7$ days & $16 \%$ \\
Outcome death & $4 \%$ \\
ICU admission & $24 \%$ \\
Hospitalization (incl. prolonged) & $69 \%$ \\
\hline
\end{tabular}

\section{Discussion}

Hypothermia in patients using an APD is a serious, unpredictable, type B adverse event frequently leading to hospital and ICU admission and sometimes even to death. Some authors have even suggested that a substantial proportion of unexplained deaths should be attributed to antipsychotic-induced hypothermia [3, 35]. No single sufficient cause for hypothermia can be found in case reports. First, drug-receptor profile may play a role. Serotonin is associated with thermoregulation and APDs with a stronger affinity for the 5-HT2a receptor than for the D2-receptor (pipamperone, the atypical APDs) seem to be associated with hypothermia. The high association for relatively new drugs, like the atypical APDs, can partially be explained by reporting bias (reporting incidence for adverse drug effects is higher for new drugs and tends to decline in time; the so-called Weber-effect), but the high number of reports for risperidone should keep clinicians alert. Blocking alpha2-adrenergic receptors (e.g., chloropromazine, risperidone, clozapine, thioridazine) may also increase the hypothermic effect, by inhibiting peripheral responses to cooling (vasoconstriction and shivering). Next to this receptor profile, many patient-bound factors must be considered. Patients with pre-existing brain damage may be more susceptible to hypothermic effects. The pre-optic anterior hypothalamic region regulates body temperature. Animal studies show that lesions of this region give a hypothermic response following administration of an APD $[36,37]$. In patients with multiple sclerosis, hypothermia is also associated with thalamic lesions [38]. Studies in schizophrenic patients show that core temperature decreases following the administration of APDs [39, 40]. Our search shows a predominance of case reports for schizophrenic patients and little for other frequent APD user groups like demented or delirious elderly. In schizophrenia, thermal regulation is altered. This may be explained by changes in neurotensine levels in schizophrenia. Neurotensine (NT) is one of the most important thermoregulatory peptides that also plays a role in the antipsychotic actions of APDs. In schizophrenic patients, NT concentration in cerebro-spinal fluid (CSF) is low and will be normalized following antipsychotic drug use [41]. The hypothermic reaction is also dependent on ambient temperature. In animal studies, APD administration at ambient temperatures below $22^{\circ} \mathrm{C}$ led to hypothermia, whereas APD administration in a room temperature of $29^{\circ} \mathrm{C}$ gave no thermal response and at $32^{\circ} \mathrm{C}$ an increase in rectal temperature [41, 42]. Normally, a cold environment will result in behavior aimed at protection against the cold (taking extra blankets or clothes). APDs, however, will induce apathy and indifference, resulting in unawareness of developing hypothermia. Since some case reports also mention the co-existence of infections at the 
time of development of hypothermia, this may also play a role in the dysregulation of thermal homeostasis.

There is an ongoing discussion concerning the value of case reports and spontaneous reports in the field of drug safety. There can be no discussion that pharmacodiligence requires prospective studies, access to regulatory filings for controlled and monitored use of drugs, and some sense of relative potency for comparison between different drug entities. However, large cohorts are needed for the detection and analysis of type B reactions. Since these data are lacking, case and spontaneous reports by alert clinicians must be analyzed [43]. The outcome of such an analysis cannot be seen as solid evidence, but can help to get more insight in the adverse drug reaction (ADR). The use of measures like ROR and disproportionality can help to detect drugs with an increased association with an ADR. A statistically significant ROR may be indicative of a higher risk for that particular event during the use of a specific medication, but is never conclusive for the actual existence of a causal relation [2].

The results of this study should alert physicians of the risk of hypothermia in psychiatric patients using APDs. There seems to be no direct relation between stable drug dose and the ADR; the period shortly after starting the APD or dose increase seems to be the high risk period. Often, drug changes are indicated by behavioral problems also leading to separation or isolation of the patient. In the case of separation, patients will be dressed lightly and, even at normal room temperature, can cool down easily. In these cases, the patient's body temperature should be monitored daily (with a thermometer that can measure low body temperatures). Also, every change in behaviour or comorbidity (e.g., infections) should be a warning sign to look for hypothermia.

Acknowledgement The authors are indebted to the national pharmacovigilance centres that contributed data for this study. The opinions and conclusions, however, are not necessarily those of the various centres, nor of the WHO.

\section{References}

1. Healy D (2002) The creation of psychopharmacology. Harvard University Press, Cambridge, Mass.

2. Puijenbroek van EP, Diemont WL, Grootheest van AC (2003) Application of quantitative signal detection in the dutch spontaneous reporting system for adverse drug reactions. Drug Safety 26 (5):293-301

3. Young DM (1996) Risk factors for hypothermia in psychiatric patients. Ann Clin Psychiatry 8(2):93-97

4. Sinha GB, Mitra SK (1955) A case of acute chlorpromazine hydrochloride poisoning. J Indian Med Assoc 24(14):557-558

5. Mitchell JR, Surridge DH, Willison RG (1959) Hypothermia after chlorpromazine in myxoedematous psychosis. Br Med $\mathrm{J} 2$ (5157):932-933
6. Jones IH, Meade TW (1964) Hypothermia following chlorpromazine therapy in myxoedematous patients. Gerontol Clin (Basel) $55: 252-256$

7. Haugan S (1966) Accidental hypothermia during treatment with a neuroleptic agent. Nord Med 75(14):377-380 (In Norwegian)

8. Loughnane T (1968) Hypothermia in a young adult. Lancet 2 (7565):455-456

9. Bevegard S, Thorstrand C (1972) Central hemodynamics in severe poisoning by hypnotic drugs. Acta Med Scand 191 (4):325-331

10. Motin J, Bouletreau P, Petit P, Latarjet J (1973) Accidental hypothermia during poisoning with neuroleptics and barbiturates. Lyon Med 230(13):53-62 (In French)

11. Scialli JV, Thornton WE (1978) Toxic reactions from a haloperidol overdose in two children. Thermal and cardiac manifestations. JAMA 239(1):48-49

12. Monteiro Filho RC, Bojikian BU, Matsubara LS, Trezza E (1980) Hypothermia - clinical, laboratory and electrocardiographic changes. Report of a case. Arq Bras Cardiol 35(2):151-154 (In Portuguese)

13. Lanska D, Harsch HH (1984) Hypothermic coma associated with thioradizine in a myxedematous patient. J Clin Psychiatry 45 (4):188-189

14. Noto T, Hashimoto H, Sugae S, Okamoto K, Nakao J, Kamimura H, Nakajima T (1987) Hypothermia caused by antipsychotic drugs in a schizophrenic patient. J Clin Psychiatry 48(2):77-78

15. Li C, Gefter WB (1992) Acute pulmonary edema induced by overdosage of phenothiazines. Chest 101(1):102-104

16. Maier U, Aigner JM, Klein HE (1994) Hypothermia caused by neuroleptics. 2 case reports and review of the literature. Nervenarzt 65(7):488-491

17. Harada H, Igarashi M, Sugae S, Okamoto K, Tsuji M, Nakajima T (1994) A schizophrenic patient who developed extreme hypothermia after an increase in the dose of haloperidol: a case report. Jpn J Psychiatry Neurol 48(3):595-598

18. Eikenboom HC, Janssens AR, Rosekrans PC, Molendijk W (1997) Hypothermia during use of pipamperone. Ned Tijdschr Geneeskd 141(6):301-303 (In Dutch)

19. Schwaninger M, Weisbrod M, Schwab S, Schroder M, Hacke W (1998) Hypothermia induced by atypical neuroleptics. Clin Neuropharmacol 21(6):344-346

20. Phan TG, Yu RY, Hersch MI (1998) Hypothermia induced by risperidone and olanzapine in a patient with Prader-Willi syndrome. Med J Aust 169(4):230-231

21. Hamuro A, Miyaoka H, Iguchi T, Kamijima K (1999) Hypothermia developing during neuroleptic treatment. Pharmacopsychiatry 32(6):258-259

22. Joye F, Orrillard M, Marion F, Michoux I, Parisot R (1999) Severe intoxication probably from olanzapine (Zyprexa). Beneficial effect of glucagon. Ann Fr Anesth Reanim 18(6):686-690 (In French)

23. Mohan MS, Patole SK, Whitehall JS (2000) Severe hypothermia in a neonate following antenatal exposure tot haloperidol. J Paediatr Child Health 36(4):412-413

24. Fanello S, Blay M, Laine-Cessac P, Daryabin M (2001) Hypothermia induced by neuroleptics. Clinical case report. Rev Med Interne 22(8):764-766 (In French)

25. Parris C, Mack JM, Cochiolo JA, Steinmann AF, Tietjen J (2001) Hypothermia in 2 patients treated with atypical antipsychotic medication. Clin Psychiatry 62(1):61-63

26. Hagg S, Mjorndal T, Lindqvist L (2001) Repeated episodes of hypothermia in a subject treated with haloperidol, levomepromazine, olanzapine and thioridazine. J Clin Psychopharmacol 21 (1):113-115

27. Chen KC, Yang YK, Chen PS, Yeh TL, Yang MJ (2003) Two case studies of hypothermia induced by an increased dosage of zotepine in a combination therapy. Psychiatry Clin Neurosci 57 (4):369-371 
28. Brevik A, Farver D (2003) Atypical antipsychotic induced mild hypothermia. S D J Med 56(2):67-70

29. Fukunishi I, Sato Y, Kino K, Shirai T, Kitaoka T (2003) Hypothermia in a hemodialysis patient treated with olanzapine monotherapy. J Clin Psychopharmacol 23(3):314

30. van Marum RJ, Jansen S, Ponssen HH (2003) Antipsychotic medication as a cause of deep hypothermia. Ned Tijdschr Geneeskd 147(25):1201-1204 (In Dutch)

31. Lee TW, Tsai SJ, Hwang JP (2003) Severe cardiovascular side effects of olanzapine in an elderly patient: case report. Int J Psychiatry Med 33(4):399-401

32. Razaq M, Samma M (2004) A case of risperidone induced hypothermia. Am J Ther 11(3):229-230

33. Blass DM, Chuen M (2004) Olanzapine associated hypothermia. Psychosomatics 45(2):135-139

34. Al Chekakie MO, Ketz JM, Whinney CM (2006) Hypothermia in a patient receiving risperidone and paroxetine. J Clin Psychopharmacol 26(3):332

35. Mehtonen OP, Aranko K, Malkonen L (1991) A survey of sudden death associated with the use of antipsychotics or antidepressant drugs: 49 cases in Finland. Acta Psychiatr Scand 84:58-64
36. Chai CY, Lin MT (1977) The enhancement of chlorpromazineinduced hypothermia by lesions in the anterior hypothalamus. $\mathrm{Br} \mathrm{J}$ Pharmacol 61(1):77-82

37. de la Cruz F (1988) Hypothermia elicited by haloperidol in rats with hypothalamic lesions. Exp Neurol 99(1):234-238

38. White KD, Scoones DJ, Newman PK (1996) Hypothermia in multiple sclerosis. J Neurol Neurosurg Psychiatry 61(4):369-375

39. Shiloh R, Weizman A, Epstein Y, Rosenberg SL, Valevski A, Dorfman-Etrog P, Wiezer N, Katz N, Munitz H, Hermesh H (2001) Abnormal thermoregulation in drug-free male schizophrenia patients. Eur Neuropsychopharmacol 11(4):285-288

40. Heh CW, Herrera J, DeMet E, Potkin S, Costa J, Sramek J, Hazlett E, Buchsbaum MS (1988) Neuroleptic-induced hypothermia associated with amelioration of psychosis in schizophrenia. Neuropsychopharmacology 1(2):149-156

41. Sharma RP, Janicak PG, Bissette G, Nemeroff CB (1997) CSF neurotensin concentrations and antipsychotic treatment in schizophrenia and schizoaffective disorder. Am J Psychiatry 154(7):1019-1021

42. Lin MT, Wang HS, Wang Z, Chern YF (1979) Haloperidol produces hypothermic effects in rats. Experientia 35(11):1469-1470

43. Vandenbroucke JP (2001) In defense of case reports and case series. Ann Intern Med 134:330-334 